\title{
A Comparative Study on Nutritional Status of Urban and Rural Early Adolescent School Girls of West Bengal, India
}

\author{
Maiti S ${ }^{1}$, Ali KM², De D³, Bera $\mathrm{TK}^{4}$, Ghosh $\mathrm{D}^{5}$, Paul $\mathbf{S}^{6}$ \\ ${ }^{1}$ Soumyajit Maiti, M.Sc. Research Scholar, ${ }^{2}$ Kazi Monjur Ali, M.Sc. Research Scholar; ${ }^{3}$ Debasis De, M.Sc. Research \\ Scholar, ${ }^{4}$ Tushar Kanti Bera, M.Sc. Research Scholar; ${ }^{5}$ Prof. Debidas Ghosh, M.Sc. PhD. Professor and HOD, \\ ${ }^{6}$ Dr. Shyamapada Paul M.Sc. Ph.D. All from the Department of Bio-Medical Laboratory Science \& Management, \\ Vidyasagar University (U.G.C Innovative Department), Midnapore - 721 102, West Bengal, India, 5,6 Nutrition \& Dietetics \\ Unit, Department of Bio-Medical Laboratory Science and Management, Vidyasagar University, Midnapore - 721102 , \\ West Bengal, India. ${ }^{1,5,6}$ Rural Research Institute of Physiology \& Applied Nutrition (RRIPAN)‘Gitanjali’, Dr. Nilay Paul \\ Road, Midnapore - 721 101, West Bengal, India.
}

Address for correspondence: Prof. Debidas Ghosh, E-mail: debidas_ghosh@yahoo.co.in, debidasghosh60@gmail.com

\begin{abstract}
Objectives: Adolescents remain largely neglected and especially girl from a deprived section in our society. The present study is an attempt to evaluate the nutritional status of early adolescent school girl from rural and urban areas. The study was, therefore, carried out to determine and compare the nutritional status of adolescent girl attending urban and rural secondary schools in Paschim Medinipur district of West Bengal, India. Methods: Cross-sectional data based on anthropometric measurements (height, weight) was collected from 2545 girls aged 10 to 14 years attending Govt. approved schools in Kharagpur town and Dantan-II block. The nutritional status has been assessed with the help of some anthropometric indices. The weight and height were recorded for each girl, and converted to nutritional indices (weightfor-age, height-for-height, BMI-for-age Z-scores of the National Center for Health Statistics reference standrads). Results: The mean nutritional indices (underweight, stunting and thinness) were found to be much lower among the rural girl than urban girl. The overall prevalent rates of underweight, stunting and thinness were $27.9 \%, 32.5 \%$ and $20.2 \%$ respectively. In the rural area these were $35.4 \%, 35.7 \%$ and $26.3 \%$, while in the urban they were $19.6 \%, 29.0 \%$ and $13.6 \%$ respectively. Conclusions: The present study shows that undernutrition constituted major health problems among early adolescent school girls in rural areas of India. Hence, the special emphases are needed to formulate various developmental and healthcare programmes for rural communities to prevent undernutrition.
\end{abstract}

Key words: Nutritional status, Early Adolescent girls, Rural, Urban

\section{Introduction}

Health and nutritional status are two crucial and interlinked aspects of human development, which in turn interact with demographic variables in important ways ${ }^{1}$. Nutritional status is now recognized to be a prime indicator of the health of individuals or community 2 . The World Health Organization (WHO) believes that the ultimate objective of nutritional assessments is the improvement of human health ${ }^{3}$. Assessing the nutritional status of groups of children is an essential part of monitoring the health of a community ${ }^{4}$. Anthropometric measurements remain the most practically useful means for the assessment of the nutritional status of a population ${ }^{5}$. Generally, three anthropometric indicators are often used to assess nutritional status during childhood and adolescent stage: underweight (weightfor-age), stunting (height-for-age) and thinness (BMI-forage $)^{6}$. The use of appropriate anthropometric indicators allows determining the nature and extent of malnutrition in the rural and urban community.

Among adolescents, girls are more vulnerable, particularly in developing countries including India, due 
to various adverse socio-cultural and socio-economic reasons ${ }^{7}$. The young girls who are at the brink of womanhood constitute the most crucial segment of our population from point of view of the quality of our future generation ${ }^{8}$. The $10-12$ years age group is a preparatory stage in the life cycle of an individual when reservoir pools of nutrients are built up in preparation for second growth spurt in life i.e. adolescence. A well balanced diet is required during this phase to ensure normal growth and to maintain physical and mental fitness ${ }^{9}$. Undernutrition during childhood delays growth and undernutrition in the years preceding adolescence delays the appearance of the adolescent spurt ${ }^{10}$. Children and adolescents are a critical resource whose growth and well being will determine to a large extent the course of a country's social and economic future ${ }^{11}$.

Recently emphasis has specially been directed towards adolescent girls. Few studies from India including West Bengal have been conducted to evaluate nutritional status of early adolescents by anthropometric methods ${ }^{7,12,13,14,15}$. However, there is a dearth of data on comparative study between rural and urban communities. So, considering this background in mind, the present investigation was carried out to determine and to compare the anthropometric data and nutritional status of early adolescent school girls in the rural and urban communities in Paschim Medinipur district of West Bengal, India as the rural belt is maximum in this district.

\section{Materials and methods}

\section{General Profile}

This study was conducted in early adolescent school girls of rural and urban areas of Paschim Medinipur district, state of West Bengal, India. The nature of the study was cross-sectional and comparative. Dantan-II block and Kharagpur town from the Paschim Medinipur district were selected for the study, which differ in terms of geographical location and economic growth. In Kharagpur, majority of the girls' father are working in Govt. sectors mainly in the railways. But in Dantan-II block, majority of the family members are engaged in agricultural sectors and unskilled manual labour which belong to lower socio-economic class. Five secondary schools within the two blocks were randomly selected for the study. From each of the schools $\mathrm{V}^{\text {th }}$ to $\mathrm{VIII}$ standard girls (age group of 10-14 years) were studied during 2009-2010 academic session.

\section{Age estimation}

Assignment of the children into appropriate age group is the first and foremost important step to be taken up in any age-dependent investigation, like growth and nutrition. Age of the girls was ascertained from the school registers.

\section{Anthropometric Profile}

The anthropometric measurements including height and weight of each subject were measured using standard techniques ${ }^{16}$ by trained investigators. Height and weight were measured to the nearest $0.1 \mathrm{~cm}$ and $0.5 \mathrm{~kg}$, respectively.

Body Mass Index (BMI) was calculated as weight in $\mathrm{kg}$ divided by square of height in metre.

\section{Assessment of Nutritional Status}

The nutritional status of adolescent girls was evaluated using age specific values of height, weight and BMI from the National Centre for Health Statistics (NCHS) references data ${ }^{17}$. Here, we have adopted three anthropometric indices such as undernutrition, stunting and thinness which were calculated by Z-score using the reference values of height-for-age, weight-forage and BMI-for-age of NCHS standards respectively. The severity of undernutrition was assessed by Z-score according to the classification of World Health Organization $^{6}$. Children with Z-score below -2 of any indices were considered to be undernourished and the children with Z-score below -3 were considered to be severely undernourished.

\section{Statistical Analysis}

The data was compiled on overall, age-wise, urban and rural and the difference between nutritional status was determined. All statistical analyses were performed using the Statistical Package for Social Sciences (SPSS, Version 7.5.1, 1996).

\section{Ethical Consideration}

Appropriate ethical permission for human studies was obtained from all concerned authorities before commencement of the study. School authorities consent was also obtained prior to the conduction of the study by focusing the nature and purpose of the said work.

\section{Results}

A total of 2545 girls were included in the present study. Of these, 1335 (52.46\%) and 1210 (47.54\%) were from the rural and urban communities, respectively. Table 1 compares the weight, height and BMI of the rural and urban school girls. It showed that in all the parameters (weight, height and BMI) the means in the urban girl were higher than those of rural girl. The difference in overall weight $(<0.05)$, height $(>0.01)$ and $\mathrm{BMI}(>0.05)$ was statistically significant. 
The comparison of the nutritional status (weight-forage) presented in table 2 . The prevalence of underweight ( $\geq-2 \mathrm{Z}$ score) in the rural and the urban communities were $35.7 \%$ and $19.7 \%$, respectively, giving an overall prevalence of underweight as $27.9 \%$. The prevalence of moderate stunting (Z-score between -2 and -3) was found to be higher in rural girls $(33 \%)$ than urban girls $(18.4 \%)$. Age-wise distribution revealed that in all rural and urban areas revealed higher prevalence of severe underweight was in 14 years age and 11 years age, respectively. But the extent of normal weight in rural areas was higher.

Table 3 compares the nutritional status (height-forage) among the rural and urban adolescent school girl. The overall prevalent rate of stunting ( $\geq-3 Z$ score) was $32.5 \%$. Among the rural girl frequency of stunting was $35.5 \%$ while in urban girl it was reduced to $19.6 \%$. When the age wise prevalence of stunting was considered, the highest prevalence of severely stunted was observed to be among 13 year old girls (19.8\%) in rural communities and similarly $14 \%$ in urban communities. In our study, both rural and urban girls showed similar frequency of moderate underweight.
Table 4 demonstrates that the nutritional status (BMl-for-age). In In the rural area, the prevalence of moderate thinness ( -2 to $-3 \mathrm{Z}$ score) was $23.3 \%$, and it is ranged from $20.4 \%$ to $28.7 \%$. But in urban area it was only $12.9 \%$. and ranged from $7.2 \%$ to $16.5 \%$. The highest prevalent rate of severe underweight of $5.6 \%$ was found among 10 year of age in rural girl. While in urban girl it was only $1.1 \%$. A total of $73.7 \%$ rural and $86.4 \%$ urban girls were normal with a highest of $79.5 \%$ in age 13 and $92.8 \%$ in age of 14 year, respectively.

The comparison of overall nutritional status was presented in figure 1. The results showed that among rural girl the frequency of underweight $(35.7 \%)$, stunting $(35.5 \%)$ and thinness $(26.3 \%)$; where as in urban girl nutritional indices were much higher. Among urban girl underweight, stunting and thinness were $29.5 \%$, $19.6 \%$ and $13.6 \%$, respectively. The overall prevalence of underweight, stunting and thinness among early adolescents in the present investigation was observed to be $27.9 \%, 32.5 \%$ and $20.2 \%$ respectively.

Table 1: Comparisons of weight, height and BMI of rural and urban early adolescent girls.

\begin{tabular}{|l|c|c|c|}
\hline Parameters & Rural & Urban & p-value \\
\hline Weight (Kg) & $29.29 \pm 6.61$ & $32.64 \pm 8.60$ & $<0.05$ \\
\hline Mean (SD) & $137.51 \pm 10.52$ & $140.03 \pm 10.01$ & $>0.01$ \\
\hline Height (cm) & $15.40 \pm 2.65$ & $16.42 \pm 2.91$ & $>0.05$ \\
\hline Mean (SD) & \\
\hline BMI (kg/m $\left.{ }^{2}\right)$ &
\end{tabular}

Table 2: Nutritional status of rural and urban early adolescent girl according weight-for-age.

\begin{tabular}{|c|c|c|c|c|c|c|}
\hline \multirow[t]{2}{*}{ Age (years) } & \multicolumn{3}{|c|}{ Rural (N=1335) } & \multicolumn{3}{|c|}{ Urban $(\mathrm{N}=1210)$} \\
\hline & $\geq-2$ Z Score & $\begin{array}{c}-2 \text { to }-3 \mathrm{Z} \\
\text { Score }\end{array}$ & $\geq-3$ Z Score & $\geq-2$ Z Score & $\begin{array}{c}-2 \text { to }-3 \mathrm{Z} \\
\text { Score }\end{array}$ & $\geq-3$ Z Score \\
\hline 10 & $216(68.0)$ & $96(30.2)$ & $6(1.8)$ & $214(80.1)$ & $50(18.7)$ & $3(1.1)$ \\
\hline 11 & $204(65.7)$ & $102(32.9)$ & $4(1.3)$ & $235(80.2)$ & $53(18.1)$ & $5(1.7)$ \\
\hline 12 & $194(67.6)$ & $85(29.6)$ & $8(2.8)$ & 209 (75.2) & $65(23.4)$ & $4(1.4)$ \\
\hline 13 & $203(65.1)$ & $104(33.3)$ & $5(1.6)$ & $240(83.0)$ & $48(16.6)$ & $1(0.3)$ \\
\hline 14 & $46(42.6)$ & $54(50.0)$ & $8(7.4)$ & $75(90.4)$ & $7(8.4)$ & $1(1.2)$ \\
\hline Total & $863(64.7)$ & $441(33.0)$ & $31(2.3)$ & $973(80.4)$ & $223(18.4)$ & $14(1.2)$ \\
\hline
\end{tabular}

$\geq-2$ Z score $=$ Normal, -2 to -3 Z score $=$ Moderate, $\geq-3$ Z score $=$ Severely Stunted

Figures in parentheses denote percentages 
Table 3: Nutritional status of rural and urban early adolescent girl according height-for-age.

\begin{tabular}{|c|c|c|c|c|c|c|}
\hline \multirow{2}{*}{ Age (years) } & \multicolumn{3}{|c|}{ Rural (N=1335) } & \multicolumn{3}{|c|}{ Urban $(\mathrm{N}=1210)$} \\
\hline & $\geq-2$ Z Score & $\begin{array}{c}-2 \text { to }-3 \mathrm{Z} \\
\text { Score } \\
\end{array}$ & $\geq-3$ Z Score & $\geq-2$ Z Score & $\begin{array}{c}-2 \text { to }-3 Z \\
\text { Score }\end{array}$ & $\geq-3$ Z Score \\
\hline 10 & $212(66.6)$ & $72(22.6)$ & $34(10.6)$ & $202(75.6)$ & $50(18.7)$ & $15(5.6)$ \\
\hline 11 & $206(66.4)$ & $65(20.9)$ & $39(12.5)$ & $210(71.6)$ & $71(24.2)$ & $12(4.1)$ \\
\hline 12 & $181(63.1)$ & $57(19.8)$ & $49(17.1)$ & $183(65.8)$ & $56(20.1)$ & $39(14.0)$ \\
\hline 13 & $188(60.2)$ & $62(19.8)$ & $62(19.8)$ & $215(74.3)$ & $58(20.1)$ & $16(5.5)$ \\
\hline 14 & $71(65.7)$ & $25(23.1)$ & 12(11.1) & $49(59.1)$ & $29(34.93)$ & $5(6.1)$ \\
\hline Total & $858(64.3)$ & $281(21.0)$ & $196(14.7)$ & $859(71.0)$ & $264(21.8)$ & $87(7.2)$ \\
\hline
\end{tabular}

$\geq-2$ Z score $=$ Normal, -2 to -3 Z score $=$ Moderate, $\geq-3$ Z score $=$ Severely Stunted

Figures in parentheses denote percentages

Table 4: Nutritional status of rural and urban early adolescent girl according BMI-for-age.

\begin{tabular}{|c|c|c|c|c|c|c|}
\hline \multirow[t]{2}{*}{ Age (years) } & \multicolumn{3}{|c|}{ Rural (N=1335) } & \multicolumn{3}{|c|}{ Urban $(\mathrm{N}=1210)$} \\
\hline & $\geq-2$ Z Score & $\begin{array}{c}-2 \text { to }-3 \mathrm{Z} \\
\text { Score }\end{array}$ & $\geq-3$ Z Score & $\geq-2$ Z Score & $\begin{array}{c}-2 \text { to }-3 \mathrm{Z} \\
\text { Score }\end{array}$ & $\geq-3$ Z Score \\
\hline 10 & $235(73.8)$ & $65(20.4)$ & $18(5.6)$ & $235(88.0)$ & $29(10.9)$ & $3(1.1)$ \\
\hline 11 & $216(69.6)$ & $85(27.4)$ & $9(2.9)$ & $250(85.3)$ & $40(13.7)$ & $3(1.0)$ \\
\hline 12 & $208(72.5)$ & $69(24.0)$ & $10(3.5)$ & $230(82.7)$ & $46(16.5)$ & $2(0.7)$ \\
\hline 13 & $248(79.5)$ & $61(19.5)$ & $3(1.0)$ & $254(87.9)$ & $35(12.1)$ & $0(0.0)$ \\
\hline 14 & $77(71.3)$ & $31(28.7)$ & $0(0.0)$ & $77(92.8)$ & $6(7.2)$ & $0(0.0)$ \\
\hline Total & 984(73.7) & $311(23.3)$ & $40(3.0)$ & $1046(86.4)$ & $156(12.9)$ & $8(0.7)$ \\
\hline
\end{tabular}

$\geq-2 \mathrm{Z}$ score $=$ Normal, -2 to $-3 \mathrm{Z}$ score $=$ Moderate,$\geq-3 \mathrm{Z}$ score $=$ Severe under Nourished

Figures in parentheses denote percentages

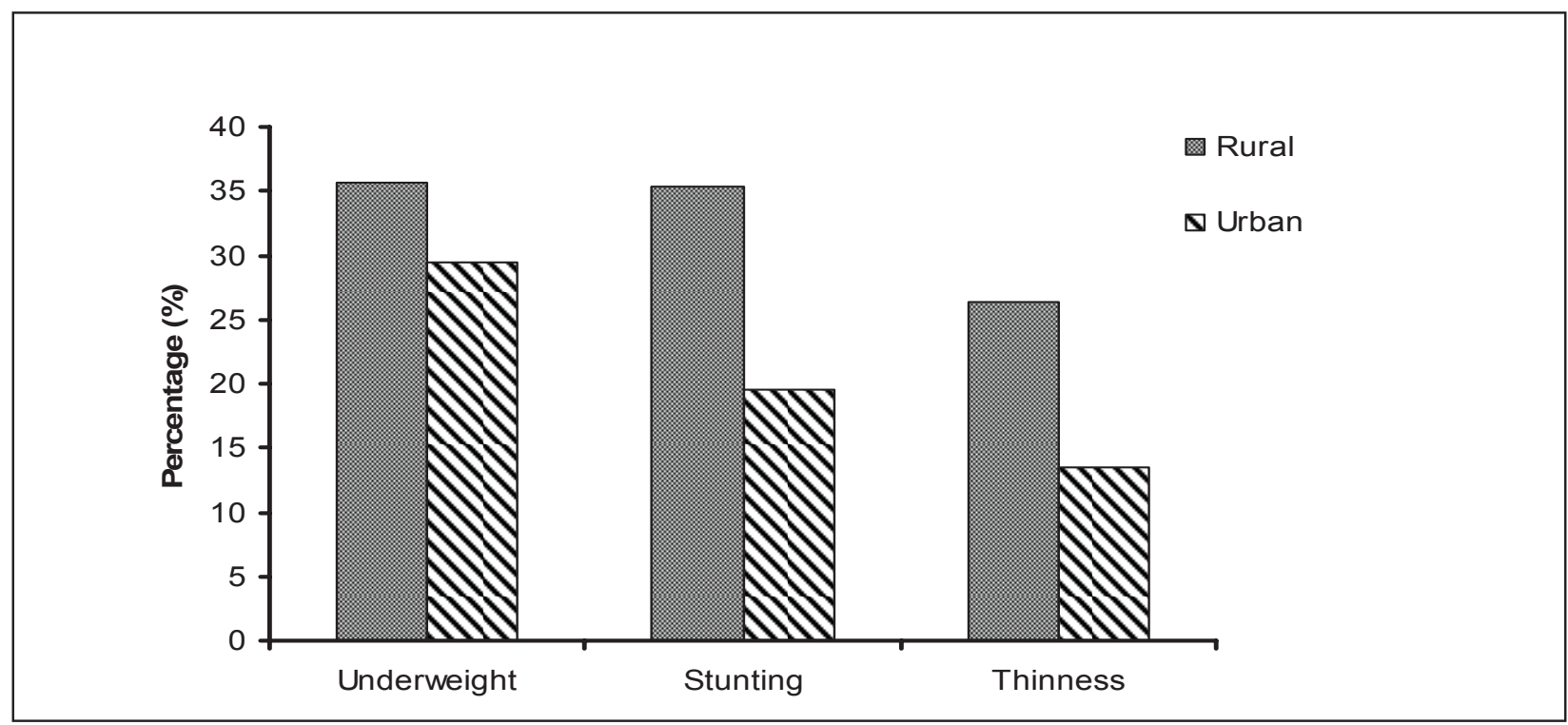

Fig 1: Comparison of underweight, stunting and thinness among rural and urban adolescent girl

\section{Discussion}

The assessment of nutritional status among the early adolescent girls in India has not been investigated sufficiently. In general, health and nutritional studies of adolescent girls in rural India are neglected, discriminated in terms of income distribution and social status, which tend to have higher rates of undernutrition ${ }^{7,18}$. The prevalence of undernutrition in adolescent is an indicator of community health status. Nutritional assessment in the community serves as appropriate data gathering processes to enable accurate planning to reduce morbidity and mortality associated with undernutrition ${ }^{2}$. 
The present investigation is based on the WHO proposed cut-offs given for the assessment of undernutrition among adolescents in terms of underweight (weight-for-age), stunting (height-for-age) and thinness (BMI-for-age). Overall prevalence of stunting $(32.5 \%)$, underweight $(27.9 \%)$ and thinness $(20.2 \%)$ in early adolescent girl was high. This study demonstrates a remarkable difference between urban and rural girls in terms of undernutrition (underweight, stunting and thinness). The higher prevalence of undernutrition in rural adolescent girls is consistent with other reports ${ }^{14,19,20}$. It is well documented that rural girls are more likely to suffer from undernutrition than urban girls.

The results revealed that the nutritional status of the rural early adolescent girl reveals a gloomy picture. There are huge differences on overall prevalence of stunting ( $\leq-2 \mathrm{Z}$ score) between urban $(19.6 \%)$ and rural $(35.5 \%)$ communities. This is similar to the findings of Oninla et al on Nigerian school children ${ }^{19}$. The prevalence of severe stunting ranged between $10.6 \%$ to $19.8 \%$ in rural girls and $4.1 \%$ to $14 \%$ in urban girls. It is interesting to note that the prevalence of moderate stunting ( -2 to -3 Z score) was same in both communities but severe stunting ( $\geq-3 Z$ score) was double in rural sectors than the urban sectors. A high prevalence of stunting (41\%) has also been documented from rural India by Anand et $\mathrm{al}^{15}$. The high prevalence of stunting reflects the compromised overall health in this population,

The total thinness ( $\leq-2 Z$ score) appears to be much higher in rural girls $(26.3 \%)$ compare to urban counterparts $(13.6 \%)$, indicating that the rural girls were experiencing acute undernutrition. The prevalence of thinness was higher in the 11-12 age groups of girls in both of the areas, but moderate grade of thinness was much higher among rural girls. A similar trend has been reported by Ghosh and Bandyopadhyay ${ }^{21}$. A study conducted in the Darjeeling district of West Bengal found that the prevalence of thinness in rural adolescent girl was $32 \%\left(5^{\text {th }} \text { percentile of } \mathrm{NCHS}\right)^{13}$. But Das and Biswas $^{7}$ reported lower (17.9\%) rate of thinness among rural adolescent girl.

Disparities also exist in case of underweight among rural (35.7\%) and urban (29.5\%) girls. In school going adolescent girls of Jaipur city, the prevalence of underweight was lower than the present study ${ }^{22}$. The rates of underweight in the present study were higher than a previous study of rural adolescent girls ${ }^{14}$. Bisai et $\mathrm{al}^{12}$ recently reported that the prevalence of underweight was $23 \%$ in rural early adolescent girl of
Paschim Medinipur district, West Bengal. Undernutrition continues to be a cause of ill health and premature mortality among children and adolescent in developing countries like India ${ }^{23}$. These delicate consequences of adolescence of undernutrition were subsequently confirmed by the other researchers among different Indian communities.

The high prevalence of undernutrition among rural girl could be attributed to social and economic disparities ${ }^{19,24}$. But better nutritional status in urban girl may be attributed to the impact of better living conditions, better nutrition and improved medical facilities as well as early biological maturation ${ }^{19}$. World-wide observations have established the fact that inadequate diet and nutrition may produce stunted growth of the body that is failure of full manifestation of genetic endowment of an individual. Malnutrition during childhood delays growth and malnutrition in the years preceding adolescent delays the appearance of the adolescent spurt ${ }^{10}$.

Although determination of the main causal factors for stunting, thinness and being underweight is beyond the scope of this report. Oyemade et $\mathrm{al}^{25}$ attributed the disparity between urban and rural areas to inadequate food intake in the rural area. The fact that the majority of the population is underprivileged and reside in the rural areas also lay credence to the significance of such investigations. The lack of adequate nutrition and parasitic infections like intestinal helminthes could be inimical to this process, thereby worsening the already poor nutritional state ${ }^{26}$. It can be summarized that the early adolescents in the present investigation are facing a great risk in terms of nutritional stress which is even more pronounced among rural girls.

Hence utmost care must be exercised to promote the health and well being especially for the rural adolescent girls because this is deprived section of our society. The results of the present investigation indicated that special emphasis is needed for policy makers in their endeavour to formulate various developmental and healthcare programmes at early stage of life.

Acknowledgements: All participating subjects, school authorities are gratefully acknowledged for their help and cooperation. We would indebted to Indian Red Cross Society (Paschim Medinipur district brunch) for assistance.

Conflict of Interest: None

Permission from IRB: Not Required 


\section{References}

1. SCN (United Nation Standing Committee on Nutrition), Fifth Report on the World Nutrition Situation: Nutrition for Improved Development Outcomes, SCN, Geneva, Switzerland, 2004.

2. Osibogun A. A handbook of public health nutrition for developing countries. Lagos: Akin Osibogun consultants, 1998;48-65.

3. Beghin I, Cap M, Dujardin B. A Guide to Nutritional Assessment. Geneva, Switzerland: World Health Organization, 1988.

4. Rabasa Al, Omatara BA, Padomu MKO. Assessment of nutritional status of children in a Sub-Saharan rural community with reference to anthropometry. Sahel Med J 1998;1:15-8.

5. Laditan AAO, Johnson AOK. Nutrition and Nutritional assessment in childhood. In: Azubuike JC, Nkanginieme KEO (eds). Paediatrics and Child Health in a Tropical Region. Owerri: African Educational Services, 1999;162-5.

6. WHO. Physical Status: the use and interpretation of anthropometry: Technical report series Geneva; World Health Organization; 1995. Report No.:854.

7. Das DK, Biswas R. Nutritional status of adolescent girls in a rural area of North 24 Parganas district, West Bengal. Indian J Pub Health 2005;49:18-21.

8. Kapil U, Manocha S, Bhasin S. Dietary intake amongst well-to-do adolescent boys and girls in Delhi. Indian Pediatr 1993;30:1017-21.

9. Kumari PS, Devadas R. Growth performance and secular trends among school children of Coimbatore. Indian J Nutr \& Dietet 1990;15:355-64.

10. Tanner JM. Growth in adolescent. 2nd edn. Blackwell, Oxford;1962.

11. Kaur PN, Marwaha G, Sidhu S. Growth pattern of affluent school children of Amritsar. Anthropologist 2005;7:261-64.

12. Bisai S, Bose K, Ghosh D, De K. Growth pattern and prevalence of underweight and stunting among rural adolescents. J Nepal Paedtr Soc 2011; 31(1):17-24.

13. Mondal N, Sen J. Prevalence of stunting and thinness among rural adolescent of Darjeeling district, West Bengal, India. Italian J Pub Health 2010;7:54-60.
14. Bose K, Bisai S. Prevalence of undernutrition among rural adolescents of West Bengal, India. J Trop Pediatr 2008; 54:422-23.

15. Anand K, Kant S, Kapoor SK. Nutritional status of adolescent school children in rural north India. Indian Pediatr 1999;36:810-15

16. Lohman TG, Roche AF, Martorell R. Anthropometric standardization references manual. Chicago: Human Kinetics Books 1988;Pp:3-80.

17. National Center for Health Statistics. Growth curves for children birth: 18 years. United States: Department of Health, Education and Welfare. Publication 78, 1997.

18. Sharma S, Nagar S, Chopra G. Health awareness of rural adolescent girls: An intervention study. J Soc Sci 2009;21:99-104.

19. Oninla SO, Owa JA, Onayade AA, Taiwo O. Comparative study if nutritional status of urban and rural Nigerian school children. J Trop Pediatr 2006; 53:39-43.

20. Anwer I, Awan J. Nutritional status comparison of rural with urban school children in Faisalabad district, Pakistan. Rural \& Remote Health 2003; 3:130.

21. Ghosh J, Bandyopadhyay AR. Prevalence of thinness and overweight among urban adolescents of West Bengal, India. J Trop Pediatr 2009;340-41.

22. Goel A. Nutritional status of girls studying in a government school in Jaipur city as determined by anthropometry. Anthropologist 2009;11:225-27.

23. Nandy S, Irving M, Gordon D, Subramanian SV, Davey Smith G. Poverty, child undernutrition and morbidity: new evidence from India. Bull WHO 2005;83:210-16.

24. Subramanyam MA, Kawachi I, Berkman LF, Subramanian SV. Socioeconomic inequalities in childhood undernutrition in India: Analyzing trends between 1992 and 2005. PLOS ONE 2010; 5:e11392

25. Oyemade A, Oliugbile A, Janes MD. Health of Nigerian rural school children. J Trop Pediatr 1981; 27:101-05.

26. Ogbonna C, Okolo SN, Okonji MC. Intestinal worms and nutritional status of under-fives in Jos, Nigeria: any relationship? Nig J Clin Pract 2004;7:79-81.

\section{How to cite this article?}

Maiti S, Ali KM, De D, Bera TK, Ghosh D, Paul S. A Comparative Study on Nutritional Status of Urban and Rural Early Adolescent School Girls of West Bengal, India. J Nepal Paediatr Soc 2011;31(3):169-174. 